Dokuz Eylül Üniversitesi-Mühendislik Fakültesi Fen ve Mühendislik Dergisi Cilt 20, Sayı 58, Ocak, 2018
Dokuz Eylul University-Faculty of Engineering Journal of Science and Engineering Volume 20, Issue 58, January, 2018

DOI: $10.21205 /$ deufmd. 2018205803

\title{
Atık İçecek Kutularından Üretilmiş Alüminyumun Mekanik Özelliklerine Soğuk İşlemin Etkisi
}

\author{
Mevlüt GÜRBÜZ* \\ ${ }^{1}$ Ondokuz Mayıs Üniversitesi, Mühendislik Fakültesi, \\ Makine Mühendisliği Bölümü, 55139, Samsun. (ORCID: 0000-0003-2365-5918)
}

(Alınış / Received: 25.10.2016, Kabul / Accepted: 07.12.2017, Online Yayınlanma / Published Online:20.01.2018)

Anahtar Kelimeler Özet: $\mathrm{Bu}$ çalışmada, döküm yöntemi ile alüminyum esaslı atık Atık alüminyum, İçecek kutusu,

Döküm,

Soğuk ișlem, Mekanik özellik içecek kutularının geri kazanımı sağlanmıştır. Dökümü yapılan alüminyumun mekanik özelliklerini iyileștirmek için farklı yüzde oranlarında soğuk işlem uygulanmıştır. Soğuk işlem öncesi ve sonrası alüminyum malzemelerin mekanik özellikleri sertlik ve çekme dayanımı ölçümü ile belirlenmiștir. Malzemelerin mikroyapısı ve kristal yapısı taramalı elektron mikroskobu ve Xışını kırınımı cihazı ile analiz edilmiştir. Elde edilen sonuçlardan soğuk şekil değişimi miktarı \%31'e kadar arttıkça mekanik özelliklerin iyileștiği görülmüştür. Artan soğuk şekil değişimine bağlı olarak Vikers sertlik değeri 76HV'den 102HV'ye, çekme dayanımı ise 54MPa'dan $92 \mathrm{MPa}$ ya kadar artmıştır.

\section{Effect of The Cold Working on Mechanical Properties of Aluminum Produced From Waste Beverage Cans}

\section{Keywords}

Waste aluminum, Beverage can, Casting, Cold working, Mechanical properties

\begin{abstract}
In this study, aluminum based waste beverage cans were recovered by casting method. Cold working at different percentage were applied to improve mechanical properties of casted aluminum. The mechanical properties of aluminum materials before and after cold working were performed with hardness and tensile strength measurement. Microstructure and crystal structure of materials were analyzed with scanning electron microscopy and X-ray diffraction devices. From the results the mechanical properties were improved up to \%31 cold working rate. The Vickers hardness increased from $76 \mathrm{HV}$ to $102 \mathrm{HV}$. Tensile strength increased from $54 \mathrm{MPa}$ to $92 \mathrm{MPa}$ with increasing cold working rate.
\end{abstract}

*Sorumlu yazar: mgurbuz@omu.edu.tr 


\section{Giriş}

Alüminyum sahip olduğu hafiflik, işlenebilirlik, oksidasyon dayanımı ve elektriksel iletkenliğinden dolayı içecek kutuları, panel, otomotiv, havacilık ve elektronik sektörlerinde parçaların üretiminde kullanılan en yaygın metaldir. Alüminyumun gerek hurdadan gerekse atık içecek kutularından geri dönüșümü, cevherden alüminyum üretmek için gereken enerjiye göre yaklaşık \%90 enerji tasarrufu sağlamaktadır. $\mathrm{Bu}$ nedenle alüminyumun geri dönüșümü oldukça önemlidir [1]. Alüminyumunun atom numarası 13, atom ağırlığı 26.98 g/mol olup “+3" değerlikli bir elementtir. Ek olarak alüminyumun oda sıcaklığında yoğunluğu $2.7 \mathrm{~g} / \mathrm{cm}^{3}$ iken ergime noktası $660^{\circ} \mathrm{C}$ ve 1 sı iletkenliği $237 \mathrm{~W} /\left(\mathrm{m}^{\circ} \mathrm{K}\right)^{\prime} \mathrm{dir}$ [2].

Alüminyum cevherden birincil alüminyum ve hurdadan ikincil alüminyum olarak üretilmektedir. Hammadde olarak alümina kullanılmakta olan birincil alüminyum metal üretimi bir elektrokimyasal indirgeme reaksiyonudur. İkincil alüminyum üretiminde ise hammadde olarak atık malzemeler (hurda, atık içecek kutuları vs.) kullanılmaktadır. Bu atık malzemeler ilk olarak yağ ve diğer kirleticilerden temizlenerek sinıflandırılmaktadır. Temizlik sonrası diğer adımlar ise boya giderimi, kurutma, parçalama ve ezme aşamalarından oluşmaktadır. $\mathrm{Bu}$ ön işlemler ergitme esnasında alüminyum kayıplarını azaltmakta ve kirleticilerden kaynaklanan emisyonu düşürmektedir. İkincil alüminyum üretiminin temelini ergitme ve döküm işlemleri oluşturmaktadır. Metali eritmek için atık malzemeler firınlara beslenir ve bir karıștırıcı ile karıștırılır. Ardından saflaştırılarak arzu edilen alaşıma göre kimyasal bileşimi ayarlanır ve sonraki işleme/imalat için döküm yapılarak uygun bir forma dönüștürülür. Karıștırmalı dökümün en büyük avantajı seri üretime uygulanabilirliğinin olması, diğer yöntemlere göre daha hızlı ve daha ekonomik olmasıdır $[3,4]$. Alüminyum endüstrisi ise kullanım amaçlarına göre külçe döküm ve ișleme ingotlarını üretip döküm, haddeleme, çekme ve dövme işlemlerine tabi tutarak endüstriyel alanlara parça üreten kuruluşları kapsamaktadır [5].

Alüminyum sahip olduğu düşük yoğunluğundan dolayı otomotiv, havacılık, askeri ve elektronik uygulamalarda yaygin olarak kullanılmaktadır. Günümüzde alüminyumun mekanik özelliklerinin iyileştirilmesi, korozyon ve aşınma dayanımın artırılması için çalışmalar yoğun olarak devam etmektedir [6,7]. Alüminyumun mekanik özelliklerinin iyileştirilmesi $\mathrm{SiC}, \mathrm{B}_{4} \mathrm{C}, \mathrm{Al}_{2} \mathrm{O}_{3}, \mathrm{Si}_{3} \mathrm{~N}_{4}$ gibi seramik takviyesiyle, mekanik alaşımlamayla, sıcak ve soğuk işlem gibi süreçlerle sağlanmaktadır [7-10]. Bu süreçler sonunda akma ve çekme dayanımı, sertliği ve tokluğu gibi mekanik özellikler tanelerin yeniden düzenlenmesinden dolayı artmaktadır. $\mathrm{Bu}$ süreçlerden biri de soğuk işlemle mekanik özelliklerinin geliştirilmesidir [11]. Soğuk işlem; soğuk şekillendirme, pekleşme ve deformasyon sertleşmesi olarak da bilinmektedir. Soğuk şekillendirme genellikle metallerin ergime sıcaklıklarının yarısından daha düşük sıcaklıklarda gerçekleşmektedir. Metallerin çoğu oda sıcaklığında gerçekleşen deformasyon sırasında sertlik ve dayanımda artış gösterir. Soğuk şekil değişimi sonrası meydana gelen plastik deformasyon derecesini ifade etmek için genellikle yüzde soğuk şekil değişimi (\%SŞD) kullanılmaktadır [12].

Ekolojik, ekonomik ve sosyal yaptırımlar göz önüne alındığında, alüminyumun geri dönüşümü alüminyumdan üretilmiş parçaların sürekli kullanımı açısından oldukça önemlidir. 2013 yılında yayınlanan raporlara göre, günümüzde dünyadaki toplam alüminyum üretimi 56 
milyon tona yaklaşmış olup bunun 18 milyon tonu hurda alüminyumdan sağlanmaktadır. Toplam alüminyum üretiminin 2020'de 97 milyon ton olması öngörülmekte olup bunun 31 milyon tonunun hurda alüminyumdan sağlanacağı belirtilmektedir. En yaygın kullanılan ve geri dönüşümü yapılan atıklardan biri de alüminyum içecek kutularıdır. Dünyada alüminyum içecek kutularının toplanma oranı \%69.1 iken Avrupa'da \%70'tir. Bu oranlar Amerika için \%54.7, İngiltere için \%52, Almanya için \%91, Çin için \%99.5, Japonya için $\% 92.7$ ve Türkiye için $\% 75$ civarındadır $[13,14]$. Bu verilere göre alüminyum içecek kutularının endüstriyel olarak tekrar değerlendirilmesi büyük öneme sahiptir.

Yukarıda verilen verilere göre; atık alüminyumun geri dönüşümü ve bunlardan parça üretimi gerek günümüzde gerekse gelecekte oldukça önemli hale gelmiștir. Dolayısıyla bu çalışmada atık içecek kutularından döküm yöntemi ile alüminyum üretiminin yapılması amaçlanmıştır. Ayrıca üretilen alüminyum malzemelere farklı yüzde soğuk şekil değişimi uygulanarak soğuk işlemin mekanik özelliklere olan etkileri araştırılmıştır.

\section{Materyal ve Metot}

$\mathrm{Bu}$ çalışmada atık alüminyum içecek kutuları ergitme malzemesi olarak kullanılmıştır. Alüminyum içecek kutuları toplandıktan sonra yüzeyindeki boya giderimi için zımparalama işlemi yapılmıștır. Boya gideriminden sonra ylkama ve ultrasonik temizlemeye maruz bırakılmıștır. Yaklaşık 200g olacak şekilde atık içecek kutuları pota içerisinde fırına beslenerek yaklaşık $750{ }^{\circ} \mathrm{C}$ 'de ergitme işlemine maruz bırakılmıştır. Eriyik paslanmaz çelik kalıplara $(6 \times 15 \times 3 \mathrm{~cm})$ dökülerek Şekil 1'de görüldüğü üzere yaklaşık $6 \times 15 \times 2 \mathrm{~cm}$ boyutlarında alüminyum numuneler üretilmiştir. Döküm işleminden sonra katılaşan alüminyumlara yoğunluk ve porozite ölçümü, sertlik ve çekme testi yapabilmek için uygun boyutlarda kesilmiştir. Soğuk şekil değişiminin mekanik özelliklere olan etkisini görmek amaciyla 100-200-300-400-500-600 MPa basma gerilmeleri altında preslenerek farklı yüzde soğuk șekil değișimleri elde edilmiştir. Soğuk şekil değişimi öncesi ve sonrası üretilen malzemelerin porozite ve yoğunlukları Arşimet yöntemiyle deneysel olarak ölçülmüştür. Alüminyum malzemelerin Vikers sertlik ölçümü (HV1000B) 200g yük uygulanarak beș ayrı noktadan ölçülmüştür. Çekme cihazı ile de çekme testleri yapılmıştır (Mares Test-10ton). Üretilen alüminyumların döküm ve soğuk şekil değişimi sonrası mikroyapıları taramalı elektron mikroskobu (SEM, Jeol JSM-6610LV), kristal yapıları ise ve $X$-ışını difraksiyonu(XRD, Rikagu Rint 2200) cihazı ile analiz edilmiştir.

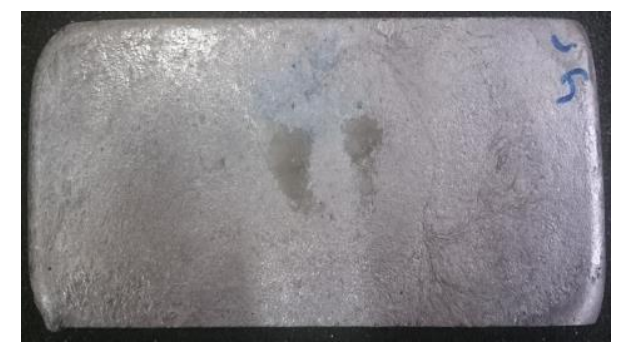

Şekil 1. Döküm yöntemiyle üretilmiş alüminyumun görüntüsü

\section{Bulgular ve Tartışma}

\subsection{Soğuk şekil değişiminin yoğunluk ve poroziteye etkisi}

Soğuk şekil değișiminin etkisini görmek için numuneler Tablo 1'de verildiği üzere 600 MPa'ya kadar farklı basınçlar altında preslenmiștir. Pres sonrası yüzde soğuk şekil değişimi (\%SŞD) aşağıdaki eşitlikten hesaplanmıştır. Burada $A_{0}$ deformasyon öncesi ilk kesit alanı, Ad ise deformasyon sonrası kesit alanını vermektedir [12].

$$
\% S S S D=\left[\left(A_{0}-A_{d}\right) / A_{0}\right] \times 100
$$


Yüzde soğuk şekil değişiminin porozite ve yoğunluğa olan etkisi Arşimet yöntemiyle aşağıdaki verilen eşitlikler kullanılarak belirlenmiștir [15]. Eșitliklerde MK kuru ağırlığı, MD doymuş ağırlığı, MA ise askı ağırlığını ifade etmektedir.

$$
\begin{aligned}
& \rho=[(M K) /(M D-M A)] \times \rho_{s u} \\
& \% P=(M D-M K) /(M D-M A) * 100
\end{aligned}
$$

Tabloda görüldüğü üzere uygulanan basma gerilmesine karşı yüzde şekil değișimi yaklașık \%6'dan \%38'a kadar artış göstermiştir.

Tablo 1. Uygulanan basma gerilmesine karşılık gelen yüzde soğuk şekil değișim miktarı.

\begin{tabular}{cc}
\hline $\begin{array}{l}\text { Basma } \\
\text { Gerilmesi(MPa) }\end{array}$ & SŞD(\%) \\
\hline 0 & 0 \\
100 & 6 \\
200 & 9 \\
300 & 11 \\
400 & 20 \\
500 & 31 \\
600 & 38 \\
\hline
\end{tabular}

Şekil 2'de ise soğuk işlem öncesi ve sonrası malzemelere ait yoğunluk ve porozite değerleri verilmiştir. Şekilde verildiği üzere \%31 SŞD’ye kadar porozite miktarı azalmakta yoğunluk ise artmaktadır. Bu değerden sonra ise aşırı plastik deformasyondan dolayı yoğunluk değeri düşerek porozite miktarı artmıştır. Soğuk işlem öncesi yoğunluk ve porozite miktarı sırasıyla $2.51 \mathrm{~g} / \mathrm{cm}^{3}$ ve $\% 6.85$ iken, \%31 SŞD'den sonra bu değerler $2.66 \mathrm{~g} / \mathrm{cm}^{3}$ ve $\% 1.58$ olmaktadır. Döküm yönteminde en çok şikâyet edilen sorunlardan birisi yapida bulunan kabarcıkların katılaşmayla yapı içinde hapsolmasıdır. $\mathrm{Bu}$ durum yoğunluğun düşmesine neden olmaktadır. Yoğunluk artışının nedeni artan soğuk şekil değişim miktarına bağlı olarak yapıdaki gözeneklerin kapanarak porozitenin azalmasıdır $[16,17]$.

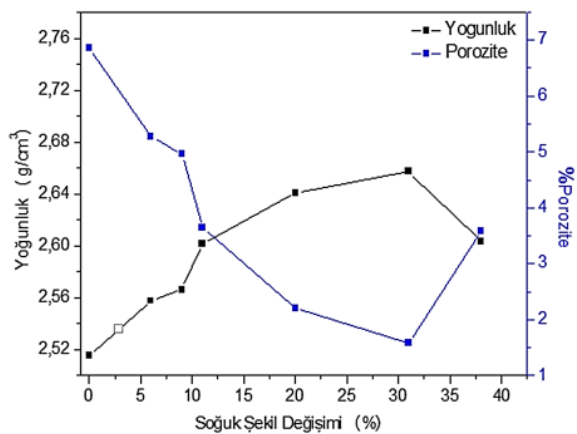

Şekil 2. \%SŞD’ye bağlı olarak yoğunluk ve gözenek değişimi

\subsection{Soğuk şekil değişiminin mikroyapıya etkisi}

Şekil 3'te üretilen alüminyumların döküm sonrası X-ışını örgü deseni verilmiştir. Görüldüğü üzere alüminyuma ait en güçlü dört difraksiyon piki $2 \theta=38.45,44.71$, 65.09 ve $78.23^{\circ}$ de elde edilmiştir (JCPDS No. 89-4037). Ayrica yapida tamamen alüminyum fazı bulunmakta olup döküm sonrası istenmeyen ikincil fazlar bulunmamaktadır.

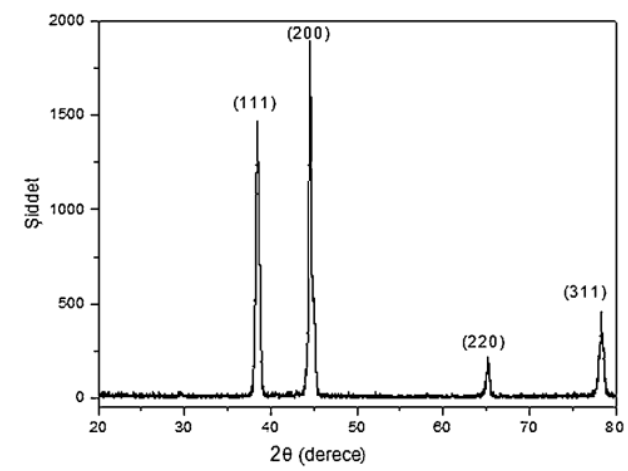

Şekil 3. Döküm yapılan alüminyumun XRD örgü deseni

Ayrıca yapılan EDX (enerji saçılımlı Xışını) analizi sonucunda döküm öncesi ve sonrası malzemede $\mathrm{Al}, \mathrm{Si}, \mathrm{Mn}, \mathrm{Mg}$ elementlerinin olduğu ve miktarlarının da birbirine oldukça yakın olduğu Tablo 2'de görülmektedir. Bir miktar Al ve Mg'de buharlaşmadan dolayı azalma meydana gelmiştir. 
Mevlüt GÜRBÜZ / Atık İçecek Kutularından Üretilmiş Alüminyumun Mekanik Özelliklerine Soğuk İşlemin Etkisi

Tablo 2. Döküm öncesi ve sonrası EDX analizi sonucu

\begin{tabular}{|c|c|c|c|c|}
\hline & $\mathrm{Al}$ & $\mathrm{Si}$ & $\mathrm{Mg}$ & $\mathrm{Mn}$ \\
\hline $\begin{array}{l}\text { Döküm } \\
\text { öncesi(ağ\%) }\end{array}$ & 94.74 & 3.60 & 0.82 & 0.84 \\
\hline $\begin{array}{l}\text { Döküm } \\
\text { Sonrası(ağ\%) }\end{array}$ & 93.82 & 4.21 & 0.72 & 1.25 \\
\hline
\end{tabular}

Üretilen alüminyum malzemeler preslenerek farklı yüzde soğuk şekil değişimine maruz bırakılmış ve malzemeye çentik açlarak darbe etkisiyle kırıldıktan sonra elde edilen kırık yüzey SEM görüntüleri Şekil 4'te verilmiştir. Şekilde \%20 soğuk şekil değişimine kadar alüminyum tanelerinin daha yuvarlak ve farklı yönlerde yönlendiği görülmektedir.
(Şekil 4a-d). Özellikle \%31 soğuk şekil değişimi için bu taneler daha çok soldan sağa doğru yönlendiği, basma gerilmesinden dolayı yukarıdan aşağıya doğru kesitin daraldığı görülmektedir. Bunun nedeni basma gerilmesine dik olarak tanenin uzamasıdır. Ayrıca tanelerin yönlenmesini daha net göstermek için tane sınırlarında renkli çizim yapıldığında \%20 soğuk şekil değişimine kadar taneler daha yuvarlak ve farklı yönde yönlenmişken $31 \%$ soğuk şekil değişiminde belli yönde uzamıș taneler daha net görülmektedir (Şekil 4f).
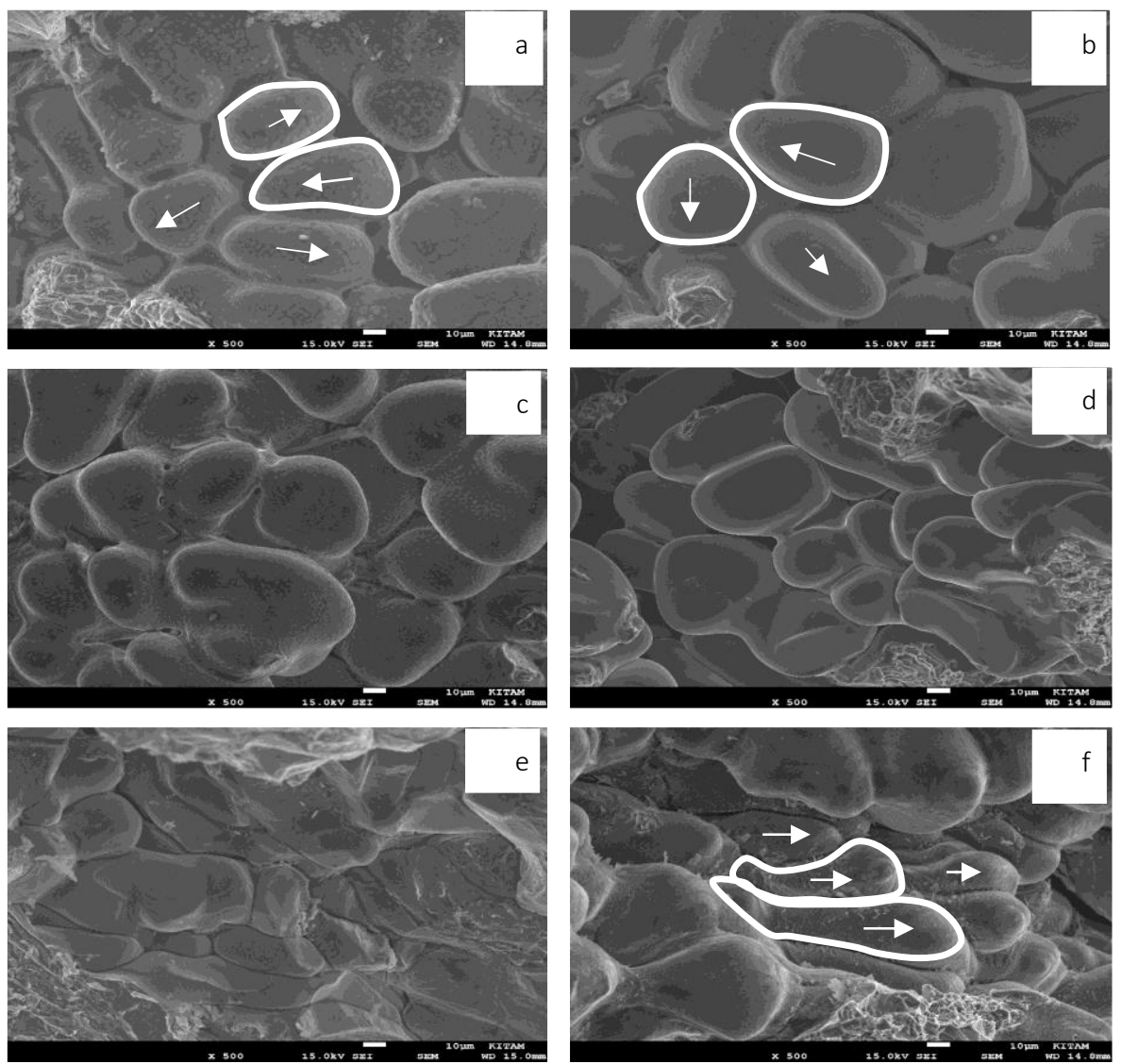

Sekil 4. Soğuk şekil değișimine maruz bırakılan alüminyum malzemelerin SEM görüntüleri: a) \%0 SȘD b) \%6 SȘD c) \%9 SȘD d) \%11 SȘD e) \%20 SȘD f) \%31 SŞD 


\subsection{Soğuk şekil değişiminin mekanik özelliklere etkisi}

Üretilen alüminyumların yüzde soğuk değişimine bağlı sertlik değerleri Şekil 5 'te verilmiştir. Sertlik ölçümü için standart metalografik numune hazırlama işlemi uygulanmıştır. Her bir malzemeden beș ayrı bölgeden ölçüm alınmıș ve ortalamaları grafikte verilmiştir. Şekilde verildiği üzere soğuk işlem öncesi üretilen alüminyum yaklaşık $75 \mathrm{HV}$ değerinde iken artan soğuk șekil değișimine bağlı olarak sertlik değeri artmaktadır. Yaklaşık \%31 soğuk şekil değişiminde sertlik değeri 102HV'ye kadar artmıștır. Fakat daha yüksek soğuk șekil değișimine maruz bırakıldığında malzemenin yan yüzeylerinde şişme meydana gelmiş ve artan basma gerilmesiyle gerek yüzeyde gerekse içyapida çatlaklar oluşmuştur. $\mathrm{Bu}$ çatlaklar gözenek gibi davrandığından sertliğin düșmesine neden olmuştur. Bu nedenle çekme testi için en iyi sertlik değerini veren \%31 SŞD tercih edilmiştir. Eriyik içerisinde bulunan kabarcıkların dökümden sonra katılaşmayla beraber hapsolması gözenek artışına sebep olmakta bu da başlangıçtaki sertliğin düşük olmasına neden olmaktadır. Çok kristalli bir metal soğuk şekil değişimine maruz kaldığında basma halinde taneler basma gerilmesine dik doğrultuda çekmede ise çekme doğrultusunda uzama gösterir. Soğuk şekil değişimi sonrası pekleşme etkisiyle ve yoğunluğun kapanan gözeneklerden dolayı artmasıyla sertlik değerinde artış görülmüştür [16-18].

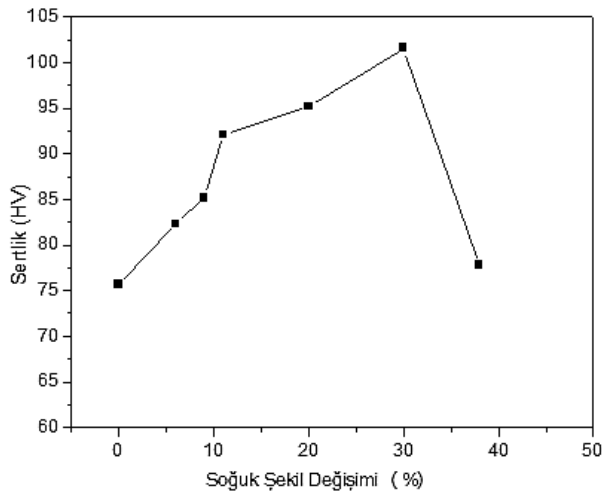

Şekil 5. Yüzde soğuk şekil değişimine bağlı olarak ortalama Vikers sertlik değerleri

Şekil 6a-b'de soğuk șekil değişimi öncesi ve sonrası elde edilen alüminyumların çekme testi sonucu gerilme birim şekil değişimi eğrileri verilmiştir. Soğuk ișlem öncesi (\%0 SȘD) maksimum çekme dayanımı yaklaşı $54 \mathrm{MPa}$ iken soğuk işlem sonrası (\%31 SŞD) bu değer 92 MPa'ya kadar artış göstermiştir. Tek fazlı metalik malzemelerin mekanik özellikleri tane boyutunun azaltılmasıyla, alaşımlamayla ve soğuk şekil değişimiyle artırılmaktadır. Özellikle sünek özellik gösteren metaller soğuk plastik șekil değișiminden sonra pekleşme nedeniyle daha yüksek çekme dayanımı ve sertliğe sahip olmaktadır. Bunun nedeni plastik deformasyona bağlı olarak dislokasyon yoğunluğunun artması gösterilebilir. Artan plastik deformasyonla dislokasyonlar arasındaki mesafeler azalmakta böylece dislokasyon hareketi bloke edilmektedir. $\mathrm{Bu}$ nedenlerden dolayı malzemenin mekanik özelliği artmaktadır [18-20]. 

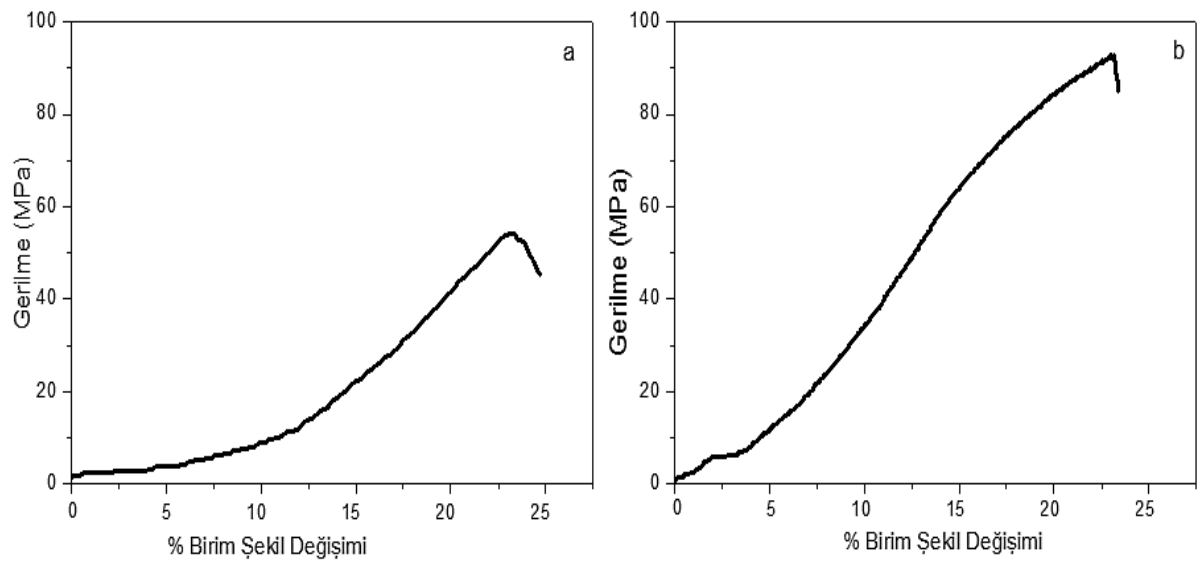

Şekil 6. Yüzde soğuk şekil değişiminin çekme mukavemetine etkisi: a) \%0 SȘD b) \%31 SȘD

\section{Sonuc}

$\mathrm{Bu}$ çalışmada atık alüminyum içecek kutularının geri dönüşümü döküm yöntemiyle başarılı bir şekilde sağlanmıștır. Döküm sonrası üretilen malzemeler farklı oranlarda yüzde soğuk şekil değișimine maruz bırakılmış ve soğuk işlemin yoğunluk, gözenek miktarı, sertlik ve çekme dayanımı üzerine olan etkisi irdelenmiștir. Yapılan XRD analizinden yapının sadece alüminyum ihtiva ettiği, SEM analizinden ise başlangıçta küresele yakın olan tanelerin artan yüzde soğuk şekil değişimine bağlı olarak eş eksenli olarak uzadığı görülmüştür. En yüksek yoğunluk $\left(2,66 \mathrm{~g} / \mathrm{cm}^{3}\right)$ ve en düşük porozite (\%1.58) \% 31 soğuk şekil değişimde elde edilmiştir. Artan yüzde soğuk șekil değișimine bağlı olarak yapılan sertlik ölçümlerinde Vikers sertlik değeri 76HV'den 102HV'ye artmıştır. Çekme dayanımı ise 54 MPa'dan 92 MPa'ya kadar artış göstermiştir.

\section{Kaynakça}

[1] Martinez, V.P, Torres, J.T., Valdes, A.F. 2017. Recycling of Aluminum Beverage Cans for Metallic Foams Manufacturing, Journal of Porous Materials. Cilt. 24, s.707-712
[2] Şenel, M.C, Gürbüz, M., Koç, E. 2015. Grafen Takviyeli Alüminyum Matrisli Yeni Nesil Kompozitler, Mühendis ve Makine, Cilt. 56, Sayı 669, s.36-47.

[3] The Aluminum Association. 2011. A North American Aluminum Industry Sustainability Report. http://www.aluminum.org/sites/def ault/files/Aluminum_The_Element_o f_Sustainability.pdf (Erişim tarihi:17.04.2017)

[4] Kala, H., Mer, K.K.S, Kumar, S.A. 2014. Review on Mechanical and Tribological Behaviors of Stir Cast Aluminum Matrix Composites, Procedia Materials Science, Cilt. 6, s.1951-1960 DOI: 10.1016/j.mspro.2014.07.229

[5] John, E. 1984. Properties of Pure Aluminum, Properties and Physical Metallurgy, ASM International, s.124.

[6] Rahimian, M., Parvin, N., Ehsani, N. 2011. The Effect of Production Parameters on Microstructure and Wear Resistance of Powder Metallurgy $\mathrm{Al}_{-}-\mathrm{Al}_{2} \mathrm{O}_{3}$ Composite, Materials and Design, Cilt. 32, s.10311038.

[7] Sharma, P., Sharma, S., Khanduja, D. 2015. Production and Some 
Properties of $\mathrm{Si}_{3} \mathrm{~N}_{4}$ Reinforced Aluminium Alloy Composites, Journal of Asian Ceramic Societies, Cilt. 3, s.352-359.

DOI: $10.1016 /$ j.jascer.2015.07.002

[8] Bastwros, M., Kim, G.Y., Zhang, C.Z.K., Wang, S., Tang, X. 2014. Effect of Ball Milling on Graphene Reinforced Al6061 Composite Fabricated by Semi-Solid Sintering, Composites: Part B, Cilt. 60, s.111-118. DOI: 10.1016/j.compositesb.2013.12.043

[9] Lianggang, G,, Shuang, Y., He, Y., Jun, Z. 2015. Processing Map of as-Cast 7075 Aluminum Alloy for Hot working, Chinese Journal of Aeronautics, Cilt. 28, No. 6, s.17741783.DOI: 10.1016/j.cja.2015.08.002

[10] Burlat, M., Julien, D., Levesque, M., Bui-Quoc, T., Bernard, M. 2008. Effect of Local Cold Working on the Fatigue Life of 7475-T7351 Aluminium Alloy Hole Specimens, Engineering Fracture Mechanics, Cilt. 75, s.20422061.DOI:10.1016/j.engfracmech.20 07.10.011

[11] Ashtiani, H.R.Z., Karami, P. 2015. Prediction of the Microstructural Variations of Cold-Worked Pure Aluminum during Annealing Process, Modeling and Numerical Simulation of Material Science, Cilt. 5, s.1-14. DOI: $10.4236 / m n s m s .2015 .51001$

[12] Callister, W.D., Rethwisch, D.G. 2014. Materials Science and Engineering, John Wiley\&Sons, Inc., Bölüm 7.10, s. 215 .

[13] Organisation of European Aluminium Refiners and Remelters, Aluminium Recycling in Europe, http://recycling.worldaluminium.or g/uploads/media/fl0000217.pdf (Erişim tarihi:20.10.2016)

[14] Organisation of European Aluminium Refiners and Remelters, Global Aluminium Recycling:A Cornerstone of Sustainable Development, http://www.worldaluminium.org/m edia/filer_public/2013/01/15/fl000 0181.pdf (Erişim tarihi:20.10.2016)

[15] German, R.M. 2007. Toz Metalurjisi ve Parçacıklı Malzeme İşlemleri, Türk Toz Metalurjisi Derneği, Bölüm 13, s.386-387

[16] Monroe, R. 2005. Porosity in Castings, AFS Transactions, 05-245(04), s.1-28.

[17] Gökmeșe, H., Bostan, B. 2013. AA 2014 Alaşımında Presleme ve Sinterlemenin Gözenek Morfolojisi ve Mikroyapısal Özelliklere Etkileri, Gazi Üniversitesi Fen Bilimleri Dergisi Part:C, Cilt1 (1), s.1-8

[18] Çapan, L. 2003. Metallere Plastik Şekil Verme, Çağlayan Kitapevi, Bölüm 2.7, s.106

[19] Mansourınejad, M., Mirzakhanı, B. 2012. Influence of Sequence of Cold Working and Aging Treatment on Mechanical Behaviour of 6061 Aluminum Alloy, Transactions of Nonferrous Metals Society of China, Cilt. 22, s.2072-2079. DOI: 10.1016/ S1003-6326(11)61430-1

[20] Hou, M.J.P., Wang, Q., Yang, H.J., Wu, X.M., Li, C.H., Li, X.W., Zhang, Z.F. 2015. Microstructure Evolution and Strengthening Mechanisms of Colddrawn Commercially Pure Aluminum Wire,Materials Science\& Engineering A ,Cilt. 639, s.103-106.

DOI: $10.1016 /$ j.msea.2015.04.102 